\title{
Fixed drug eruption induced by atenolol
}

\author{
$\mathrm{H}$ Belhadjali \\ O Trimech \\ MYoussef \\ I Elhani \\ J Zili \\ Department of Dermatology, \\ Fattouma Bourguiba Hospital, \\ Monastir, Tunisia
}

Correspondence: Hichem Belhadjali Department of Dermatology, Fattouma Bourguiba Hospital, Monastir 5000, Tunisia Tel +2 I 67346 I I 44 Ext I 290 Fax +2I 673460678

Email belhadjalihichem@yahoo.fr
Abstract: Fixed drug eruption (FDE) is characterized by recurrent well-defined lesions in the same location each time the responsible drug is taken. We report here a case of multiple FDE induced by atenolol in a 48-year-old woman confirmed by positive patch test in previously affected sites. Beta-blockers-induced FDE are very rare. Only two cases had been reported in the literature. To the best of our knowledge, this is the first case reported of atenolol-induced FDE confirmed by a positive patch test.

Keywords: fixed drug eruption, patch test, atenolol, beta-blockers

\section{Introduction}

Fixed drug eruption (FDE) is characterized by recurrent well-defined lesions in the same location each time the responsible drug is taken. We report here a rare case of FDE induced by atenolol, a beta-adrenoreceptor-blocking agent.

\section{Case study}

A 48-year-old Tunisian woman was referred to our department for the appearance of five inflammatory plaques on both legs. She had been treated for hypertension with atenolol (Hypoten ${ }^{\circledR}$, Al-Hikma Pharmaceuticals, Jordan) $100 \mathrm{mg}$ once a day for six weeks. No other medications had been taken and she had not previously received betablocking agents. The lesions had begun three weeks after the onset of atenolol. Physical examination revealed five well-demarcated reddish and round plaques with an itching and burning sensation on both legs (Figure 1). One of these lesions showed vesicular changes. The diagnosis of multiple FDE was suspected and atenolol was discontinued. Skin biopsy, taken from a lesion with no vesicular changes, showed focal necrosis of keratinocytes, hydropic degeneration of the basal cells, dermal edema and a perivascular lymphocytic infiltrate of the upper dermis. These histopathological findings were consistent with the diagnosis of FDE. Topical desonide (Locatop ${ }^{\circledR}$ ) was applied twice a day and skin lesions resolved within two weeks with a residual pigmentation. 6 weeks after complete resolution, patch testing was carried out according to the International Contact Dermatitis Research Group (Jacobs et al 1999) recommendations with 10\% atenolol in petrolatum on a previously affected site of the right leg (Figure 2) and on normal skin of the back. A positive reaction (++) was seen at D2 and D3 on the left leg but no reaction was detected on the back. Thus, the diagnosis of atenolol-induced FDE was established. There was no relapse during a follow-up period of one year.

\section{Discussion}

Several drugs can induce FDE. They mostly include nonsteroidal antiinflammatory drugs, nonopioid analgesics, sulphonamides, and tetracyclines (Savin 2001).

Topical provocation testing has been reported to be useful and safe for the diagnosis of FDE when applied on previously affected sites (Alanko et al 1987; Alanko 1994; Lee 1998; Ozkaya-Bayazit et al 1999). Patch testing in FDE is still not standardized (Ozkaya 2008). Different patch test methods (open/occlusive) and variations in their 


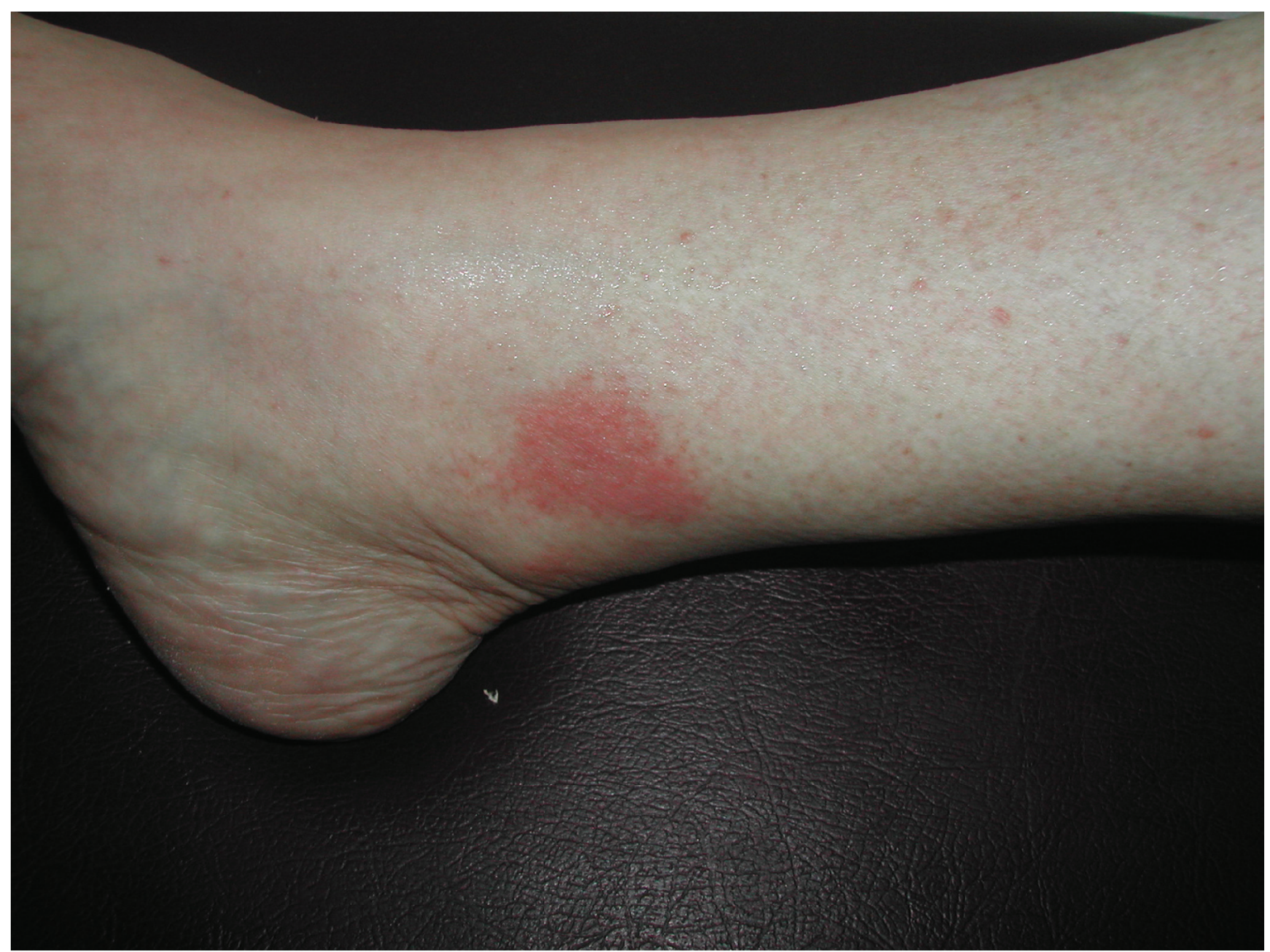

Figure I Well-demarcated plaque of the right leg with erythema and edema.

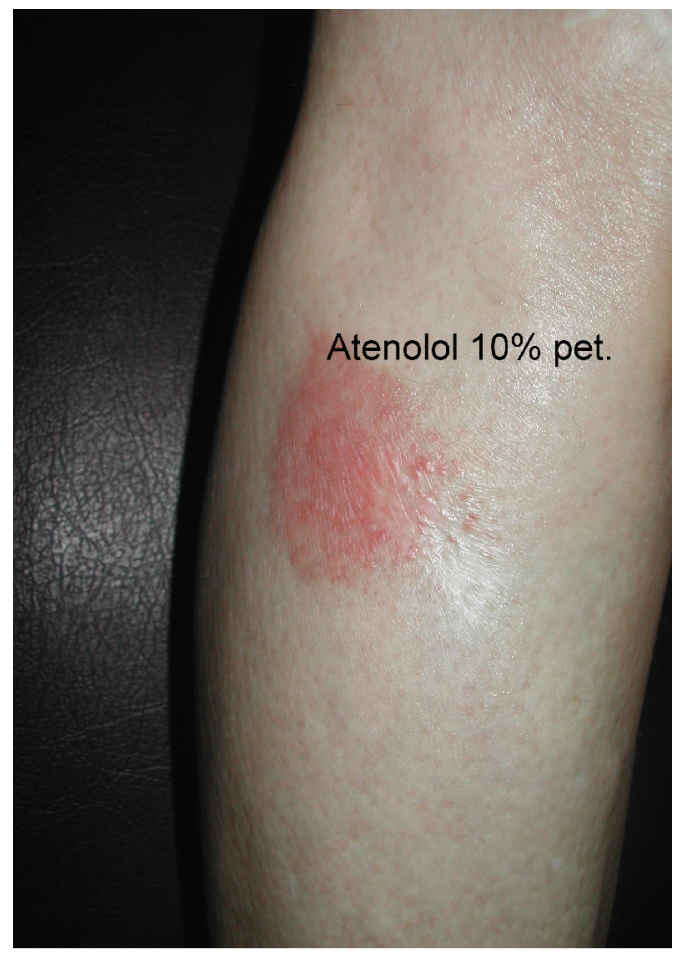

Figure 2 Positive patch test with 10\% atenolol in petrolatum. 
evaluation (erythema of more than six hours duration/ erythema and infiltration) exist (Ozkaya 2008).

Beta-blockers-induced FDE are very rare (Palungwachira and Palungwachira 1999; Zaccaria et al 2006). Only two cases have been reported in the literature (Palungwachira and Palungwachira 1999; Zaccaria et al 2006). They were induced by atenolol (Palungwachira and Palungwachira 1999) and propranolol (Zaccaria et al 2006). None of them was confirmed by patch testing or systemic provocation (Palungwachira and Palungwachira 1999; Zaccaria et al 2006). Thus, to the best of our knowledge, we report herein the first case of FDE induced by atenolol and confirmed by a positive patch test on previously affected sites.

\section{Disclosure}

The authors report no conflict of interest in this work.

\section{References}

Alanko K. 1994. Topical provocation of fixed drug eruption. A study of 30 patients. Contact Dermatitis, 1:25-7.

Alanko K, Stubb S, Reitamo S. 1987. Topical provocation of fixed drug eruption. Br J Dermatol, 116:561-7.
Jacobs MC, Tennstedt D, Lachapelle JM. 1999. [Dermatite allergique de contact.] Encycl Méd Chir (Elsevier, Paris) Dermatologie, 98-145-A-10, $14 \mathrm{p}$.

Lee AY. 1998. 1 provocation in 31 cases of fixed drug eruption: change of causative drugs in 10 years. Contact Dermatitis, 38:258-60.

Ozkaya E. 2008. Fixed drug eruption: state of the art. J Dtsch Dermatol Ges, 6:181-8.

Ozkaya-Bayazit E, Bayazit H, Ozarmagan G. 1999. Topical provocation in 27 cases of cotrimoxazole-induced fixed drug eruption. Contact Dermatitis, 41:185-9.

Palungwachira P, Palungwachira P. 1999. Fixed drug eruption to atenolol: a case report. J Med Assoc Thai, 82:1158-61.

Savin JA. 2001. Current causes of fixed drug eruption in the UK. $\mathrm{Br} J$ Dermatol, 145:667-8.

Zaccaria E, Gualco F, Drago F, et al. 2006. Fixed drug eruption due to propranolol. Acta Derm Venereol, 86:371. 